\title{
A teachable moment: A facilitator's guide to activities for processing, debriefing, reviewing, and reflection.
}

\author{
Reviewed by Glyn Thomas
}

\author{
La Trobe University, Bendigo
}

Cain, J., Cummings, M., \& Stanchfield, J. (2005). A teachable moment: A facilitator's guide to activities for processing, debriefing, reviewing and reflection. Dubuque, IO: Kendall/Hunt.

282 pages. ISBN: 0-7575-1782-X

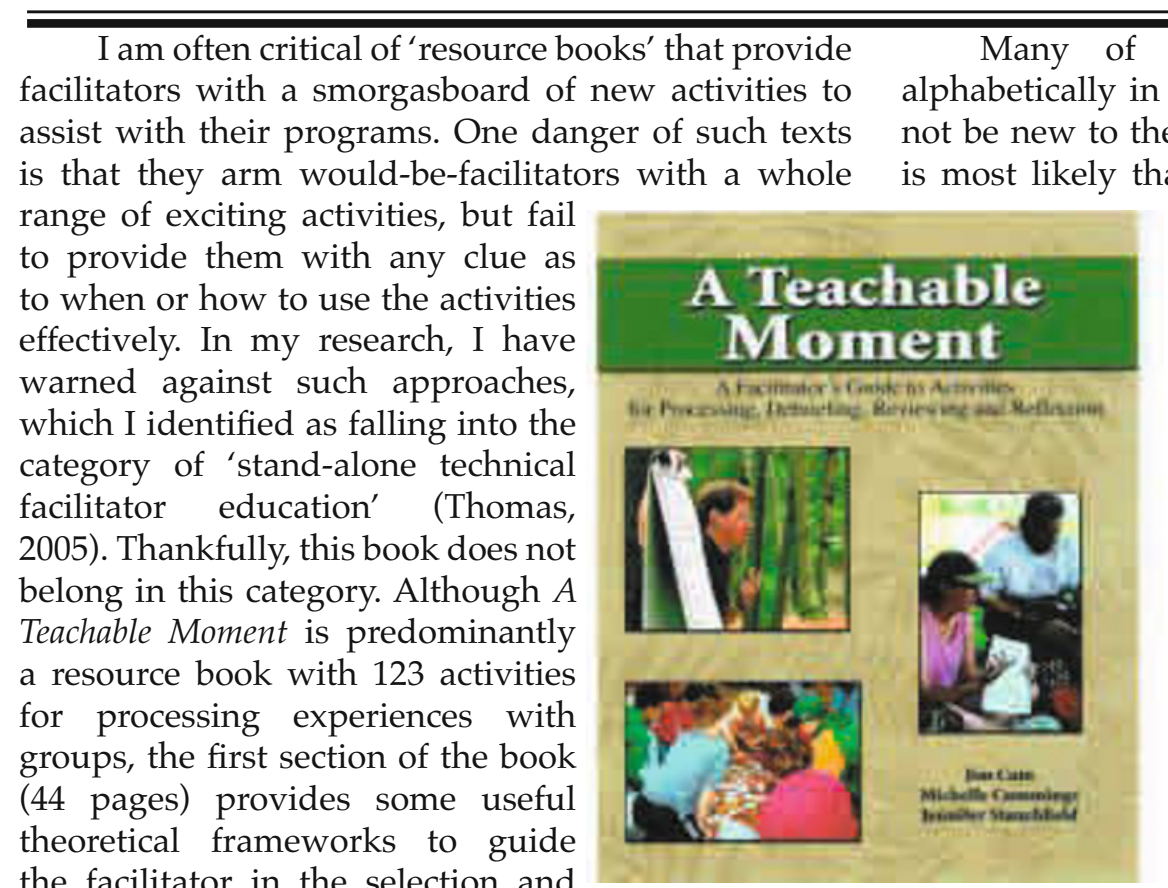

the facilitator in the selection and

effective implementation of these activities. This allows the facilitator to work towards a higher level of intentionality in their practice, where an understanding of theory and values is used to guide interventions.

Cain, Cummings, and Stanchfield draw on a number of models to guide the facilitator including: Priest and Gass's (2005) Generations of Facilitation; Tuckman and Jensen's (Tuckman \& Jenson, 1977) Stages of Group Development; and Howard Gardner's (2006) Eight Multiple Intelligences. The inclusion of these models to guide the facilitator is what separates this resource book from many others I have seen. I especially like the way the authors encourage facilitators to try and cater to the full spectrum of intelligences identified by Gardner. Other chapters in this first section of the book provide facilitator tips and style notes, a ten-step process to increase one's value as a facilitator, some tips on sequencing, and processing objectives and questions. The final chapters of the first section of the book categorise the processing tools into five areas: active and kinesthetic techniques, artistic expression, alternatives to the traditional sharing circle, and metaphoric methods and self-reflective activities. challenging for a novice to take an activity from a book and make it work first time, the key is to customise such tools suit the facilitator's style. Experienced facilitators will do this more easily, but that should not deter emerging outdoor leaders and educators from trying something new.

\section{References}

Gardner, H. (2006). Multiple intelligences: New horizons. New York: Basic.

Priest, S., \& Gass, M. A. (2005). Effective leadership in adventure programming (2nd ed.). Champaign, IL: Human Kinetics.

Thomas, G. J. (2005). Dimensions of facilitator education. In S. Schuman (Ed.), The IAF handbook of group facilitation: Best practices from the leading organisation in facilitation (pp. 525-541). San Francisco: Jossey-Bass.

Tuckman, B. W., \& Jenson, M. (1977). Developmental sequences of small groups. Group and Organisational Studies, 2, 419-427. 